\title{
Erratum to: Application of advanced light microscopic techniques to gain deeper insights into cheese matrix physico-chemistry
}

\section{Zuzana Burdikova $^{1} \cdot$ Zdenek Svindrych $^{2}$.}

Cian Hickey ${ }^{1}$ - Martin G. Wilkinson ${ }^{4}$.

Mark A. E. Auty ${ }^{1}$ - Ota Samek ${ }^{3}$ - Silvia Bernatova ${ }^{3}$.

Vladislav Krzyzanek ${ }^{3}$ - Ammasi Periasamy ${ }^{2}$.

Jeremiah J. Sheehan ${ }^{1}$

Received: 9 April 2015 /Revised: 27 July 2015 / Accepted: 28 July 2015 /

Published online: 5 October 2015

C) INRA and Springer-Verlag France 2015

\section{Erratum to: Dairy Sci. Technol. \\ DOI 10.1007/s13594-015-0253-2}

In the original paper, the affiliation for respectively authors Ota Samek, Silvia Bernatova and Vladislav Krzyzanek should have read as follows: Institute of Scientific Instruments of the CAS, Brno, Czech Republic

\footnotetext{
The online version of the original article can be found at http://dx.doi.org/10.1007/s13594-015-0253-2.
}

\section{Zuzana Burdikova}

zuzana.burdikova@teagasc.ie

$\triangle$ Jeremiah J. Sheehan

diarmuid.sheehan@teagasc.ie

1 Teagasc Food Research Centre, Moorepark, Fermoy, Co., Cork, Ireland

2 Department of Biology, University of Virginia, Charlottesville, VA, USA

3 Institute of Scientific Instruments of the CAS, Brno, Czech Republic

4 Department of Life Sciences, University of Limerick, Limerick, Ireland 